\title{
Multinational Survey of Treatment Practices of Clinicians Managing Subclinical Hypothyroidism in Older People in 2019
}

\author{
Salman Razvi ${ }^{a} \quad$ Bronia Arnott $^{b}$ Dawn Teare ${ }^{b}$ Shaun Hiu ${ }^{b}$ Nicki O'Brien ${ }^{c}$ \\ Simon H. Pearce ${ }^{a}$ \\ ${ }^{a}$ Translational and Clinical Research Institute, Newcastle University, Newcastle upon Tyne, UK; ${ }^{b}$ Population Health \\ Sciences Institute, Newcastle University, Newcastle upon Tyne, UK; ${ }^{C}$ Department of Psychology, Northumbria \\ University, Newcastle upon Tyne, UK
}

\section{Keywords}

Subclinical hypothyroidism · Older person · Levothyroxine · Thyroid hormones

\begin{abstract}
Background: International societies have recommended that levothyroxine should not routinely be prescribed in older individuals for the management of mild subclinical hypothyroidism (SCH). However, it is unknown whether clinicians managing people with $\mathrm{SCH}$ are either aware of or adhere to these guidelines. Methods: A web-based survey of members of several international thyroid associations and general practitioners in North-East England was conducted. Respondents were presented with a vignette of an 80-year-old gentleman with mild persistent $\mathrm{SCH}$ experiencing tiredness. Multivariable logistic regression analyses were performed to evaluate predictors of awareness of guidelines and responses to treatment. Results: The survey response rate was $21.9 \%$ $(565 / 2,583)$. Only $7.6 \%$ of clinicians were unaware of guidelines regarding management of $\mathrm{SCH}$ in older people. Twenty percent of clinicians stated that they would treat the older patient with mild $\mathrm{SCH}$, whereas $13 \%$ were unsure. Clinicians from North America were more likely to treat the older per-
\end{abstract}

son with mild SCH than clinicians from elsewhere (OR 2.24 [1.25-3.98]). Likewise, non-endocrinologists were also more likely than endocrinologists to treat the older person with mild SCH (OR 3.26 [1.45-6.47]). Conclusion: The majority of clinicians are aware of guidelines regarding management of $\mathrm{SCH}$ in older individuals. However, a considerable proportion of clinicians would still treat an older person with nonspecific symptoms and mild SCH. These guidelines need to be disseminated more widely and more research is required to understand barriers to adherence to international recommendations.

(c) 2020 European Thyroid Association Published by S. Karger AG, Basel

\section{Introduction}

Subclinical hypothyroidism (SCH) is a mild form of thyroid failure diagnosed when serum TSH levels are high and circulating thyroid hormones are within the reference range $[1,2]$. The prevalence of SCH increases with age and is more common in women and those with presence of thyroid autoimmunity. It is recognised that serum TSH levels increase with age [3]. Furthermore, even within the same individual, TSH levels rise over time with lit- 
tle or no change in circulating thyroxine levels $[4,5]$. Importantly, a slightly high serum TSH is not associated with any adverse effect in older people, or may even be protective [6-8]. Despite this, TSH reference ranges are uniformly applied across the age groups without reference to the patient's age. This may be responsible, at least in part, for a trend of increasing prescribing of levothyroxine (LT4) in older individuals [9]. Consequently, LT4 is the most prescribed drug in the USA and the third most prescribed drug in the UK [10]. Within the UK, LT4 use has increased over time leading to more than 1.5 million individuals over the age of 70 years being classed as having hypothyroidism as defined by LT4 use $[11,12]$. The potential long-term consequences of LT4 therapy in older people are unclear. One study has shown that the frequency of atrial fibrillation is increased in areas with higher prevalence of LT4 prescribing [13]. Other studies have demonstrated that both lower bone mineral density and fractures are associated with LT4 use $[14,15]$.

There has been long-standing debate pertaining to the merits of treating SCH [16]. This is also reflected in differences between various thyroid societies' recommendations related to the management of $\mathrm{SCH}$, particularly with regard to age. The European Thyroid Association has recommended that individuals older than 70 years with mild SCH (serum TSH $<10$ mIU/L) should not routinely be treated with LT4 therapy [17]. Other bodies such as the Latin American Thyroid Society and the Society for Endocrinology, Metabolism and Diabetes of South Africa have also suggested that the age of the patient should be considered when LT4 treatment is being contemplated $[18,19]$. However, the American Thyroid Association does not specifically highlight that age should be a criterion when considering treatment in patients with mild $\mathrm{SCH}$, although it does state that normal serum TSH reference range changes with age [20].

It is unclear whether guidelines formulated by these thyroid healthcare professional organisations are being followed with regard to the management of SCH in older individuals. We therefore conducted a multinational survey of clinicians interested in the management of thyroid disease.

\section{Methods}

\section{Survey Population}

The survey was sent electronically to all members of the European Thyroid Association, the American Thyroid Association, the Latin American Thyroid Society, the Society for Endocrinology, Metabolism and Diabetes of South Africa, and the Alexandria Thy- roid Association. The survey was sent by authorised personnel of each of the above associations to all their members via e-mail between January and June 2019 with an electronic link embedded in the body of the e-mail. A reminder e-mail was sent 4-6 weeks later to all the members. No incentive was offered for the completion of the survey. Data from the survey responses were collected automatically in an anonymised manner. Each participating association kept a record of the number of members that responded to the survey by clicking on the link. The study was approved by the Newcastle University Faculty of Medical Sciences Ethics Committee (1650/2018).

Responses from a small number of nurses $(n=4)$ of the various associations were excluded from further analysis. The survey was also distributed to general practitioners (GPs) in the Gateshead area of the Newcastle-Gateshead Clinical Commissioning Group. Since the GPs were invited from a well-defined geographical location, their responses were analysed separately and the results should be considered as preliminary data (available in online supplementary data; for all online supplementary material, see www. karger.com/doi/10.1159/000509228) and may not represent the views of GPs elsewhere.

\section{Survey Questions}

The objective of the survey was to assess the treatment decision, and awareness of and adherence to guidelines pertaining to the management of SCH in older individuals on clinical practice. The survey questions were preceded by a short hypothetical clinical scenario of an 80-year-old gentleman with sustained SCH with serum TSH levels of 6.5 and 6.8 (reference range $0.4-4.5 \mathrm{mIU} / \mathrm{L}$ ) and FT4 14.0 and 13.5 (reference range 10-22 pmol/L) on 2 separate occasions and who was experiencing tiredness. The subsequent questions were designed to elicit responses about treatment choice and awareness of guidelines pertaining to the management of SCH in an older individual. The survey was developed in English and reviewed for content validity by the authors with input provided by survey methodologists. The survey was piloted for comprehension by a group of clinicians before being finalised and disseminated via professional bodies and societies. The survey questions are provided in online supplementary data.

\section{Covariates of Interest}

In addition to the survey questions, additional information regarding the respondents was also collected. Respondents were categorised by age group $(<30,31-40,41-50,51-60,61-70,>70$ years, or prefer not to say), sex (male, female, or prefer not to say), region of practice (Europe including the UK, North America, Latin America, North Africa, South Africa, or other countries), years in practice since qualifying $(0-5,6-10,11-15,16-20,>20$ years, or prefer not to say), and their current professional role (consultant endocrinologist or equivalent, trainee endocrinologist, or other clinician). In addition, to explore potential reasons underlying regional differences in treatment decisions of the older person with $\mathrm{SCH}$, we also descriptively analysed the relationship between the guidelines formulated by each learned society with its members' treatment decision.

\section{Statistical Analysis}

Summary descriptive statistics using frequencies and percentages were obtained. The primary outcomes assessed were the decision to treat or not treat the hypothetical older person with $\mathrm{SCH}$ 
and awareness of guidelines. Other outcomes evaluated were the respondents' adherence to guidelines, and their view on whether the guidelines had improved prescribing practice for the older $\mathrm{SCH}$ population. Response rate was calculated as the percentage of members that opened the electronic link to the survey. Correlation between dichotomous variables was assessed by $2 \times 2$ chi-square testing. Multivariable logistic regression analysis was utilised to assess predictors of the primary outcomes. Covariates in this model were based on clinical plausibility and included the age group, sex, country of practice, and current role. The variable relating to years in practice was closely correlated with the respondents' age group (Spearman's rho $=0.89$ ) and hence was not included in the model, to limit collinearity. In the multivariable binary logistic regression model, responses from clinicians from North America were compared to other parts of the world, as guidelines from the American Thyroid Association are the least prescriptive with regard to not initiating treatment in older SCH individuals.

Furthermore, we evaluated evidence of change in clinical practice across several parts of the world. We conducted a one-sample proportions test with continuity correction to test the hypothesis that there is an unequal proportion of opinions. We set $\alpha=0.05$ and report the point estimate and 95\% confidence interval (CI). We also conducted a subgroup analysis and reported an adjusted $\mathrm{CI}$ to correct for multiple comparisons. To account for the potential ambiguity in the interpretation of "unsure" and "other" responses, we conducted a sensitivity analysis excluding participants who provided these responses to assess the robustness of our previous analyses. In the prior analysis, we had assumed that responses could be categorised into a clear-benefit/no-clear-benefit dichotomy. It was assumed that "unsure" and "other" responses reflected a genuine ambivalence regarding the net effect of the guidelines, which could be interpreted as the guidelines not displaying a definitively clear benefit. However, it could also reflect satisficing (e.g., low effort responding) or participants who had insufficient opportunity to exercise the guidelines to make an informed response. All statistical analyses were performed using SPSS version 24 (Chicago, IL, USA) and a $p$ value of $<0.05$ was considered as being statistically significant.

\section{Results}

\section{Response Rates and Characteristics of Respondents}

The survey was sent to 2,583 members of the various scientific bodies. Of these, 565 individuals responded, giving a response rate of $21.9 \%$. Response rates varied between the various regions, with North Africa having the highest response rate of $37.2 \%$, whereas only $6.1 \%$ of those from Latin American countries responded. Of these 565 respondents, we excluded 4 participants whose role was nurse or allied health professional and 55 participants with incomplete data, leaving 506 provided complete responses regarding their individual and clinical practicerelated details. The characteristics of these 506 respondents are shown in Table 1. The majority of respondents were aged between 31 and 70 years and included more
Table 1. Characteristics of survey respondents $(n=506)^{\mathrm{a}}$

\begin{tabular}{|c|c|c|}
\hline Characteristic & $n(\%)^{\mathrm{a}}$ & \\
\hline \multicolumn{3}{|l|}{ Age group } \\
\hline$<30$ years & $8(1.5)$ & \\
\hline $31-40$ years & $105(20.7)$ & \\
\hline $41-50$ years & $107(21.2)$ & \\
\hline $51-60$ years & $124(24.6)$ & \\
\hline $61-70$ years & $96(18.8)$ & \\
\hline$>70$ years & $64(12.4)$ & \\
\hline Prefer not to say & $2(0.4)$ & \\
\hline \multicolumn{3}{|l|}{ Sex } \\
\hline Male & $290(57.3)$ & \\
\hline Female & $213(42.1)$ & \\
\hline Prefer not to say & $3(0.6)$ & \\
\hline \multicolumn{3}{|l|}{ Region/country ${ }^{\mathrm{b}}$ of practice } \\
\hline Europe $(869)^{c}$ & $243(48.1)^{\mathrm{d}}$ & $(27.9)^{\mathrm{e}}$ \\
\hline North America $(679)^{c}$ & $131(25.9)^{\mathrm{d}}$ & $(19.3)^{\mathrm{e}}$ \\
\hline Egypt and North Africa $(78)^{\mathrm{c}}$ & $28(5.5)^{\mathrm{d}}$ & $(35.9)^{\mathrm{e}}$ \\
\hline South Africa $(184)^{\mathrm{c}}$ & $28(5.5)^{\mathrm{d}}$ & $(15.2)^{\mathrm{e}}$ \\
\hline Latin America $(773)^{\mathrm{c}}$ & $45(8.9)^{\mathrm{d}}$ & $(5.8)^{\mathrm{e}}$ \\
\hline Other $^{\mathrm{f}}$ & $31(6.1)^{\mathrm{d}}$ & \\
\hline \multicolumn{3}{|l|}{ Current role } \\
\hline Endocrinologists & $406(80.3)$ & \\
\hline Trainee endocrinologists & $20(3.8)$ & \\
\hline Other specialists & $61(12.1)$ & \\
\hline Not disclosed & $19(3.8)$ & \\
\hline \multicolumn{3}{|l|}{ How long qualified } \\
\hline $0-5$ years & $61(12.1)$ & \\
\hline $6-10$ years & $61(12.1)$ & \\
\hline $11-15$ years & $59(11.6)$ & \\
\hline $16-20$ years & $65(12.9)$ & \\
\hline$>20$ years & $257(50.8)$ & \\
\hline Not disclosed & $3(0.6)$ & \\
\hline
\end{tabular}

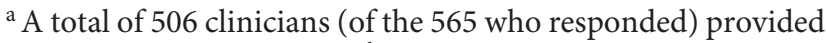
details that are described here. ${ }^{b}$ Europe included countries on the European continent such as Albania, Austria, Belgium, Bulgaria, Croatia, Denmark, Finland, France, Georgia, Germany, Greece, Hungary, Italy, Latvia, Macedonia, Moldova, the Netherlands, Norway, Poland, Portugal, Romania, Russia, Serbia, Slovakia, Slovenia, Spain, Sweden, Switzerland, Turkey, UK. North America included USA and Canada; Egypt and North Africa included Egypt and Algeria; Latin America included Argentina, Brazil, Chile, Colombia, Ecuador, Mexico, Panama, Paraguay, Peru; Others included Australia, Bangladesh, China, India, Iran, Iraq, Japan, Jordan, Malaysia, Nigeria, Pakistan, Philippines, Saudi Arabia, South Korea, Taiwan, Trinidad and Tobago, and the United Arab Emirates. ${ }^{\mathrm{c}} n=$ survey sent to. ${ }^{\mathrm{d}}$ Of total. ${ }^{\mathrm{e}}$ Percent of region. ${ }^{\mathrm{f}}$ These are clinicians who are members of the participating thyroid professional bodies but reside elsewhere.

men than women (57.3 and 42.1\%, respectively). Physicians from European countries constituted just less than half $(48 \%)$ of all the respondents, slightly more than a quarter (26\%) was from North America, and the rest from 
Fig. 1. Frequency of awareness of and adherence to clinical guidelines, and likelihood of treating an older person with subclinical hypothyroidism, by clinical/professional roles. The denominators for each group were: endocrinologists $=402$, trainee endocrinologists $=18$, other clinicians $=$ 52.

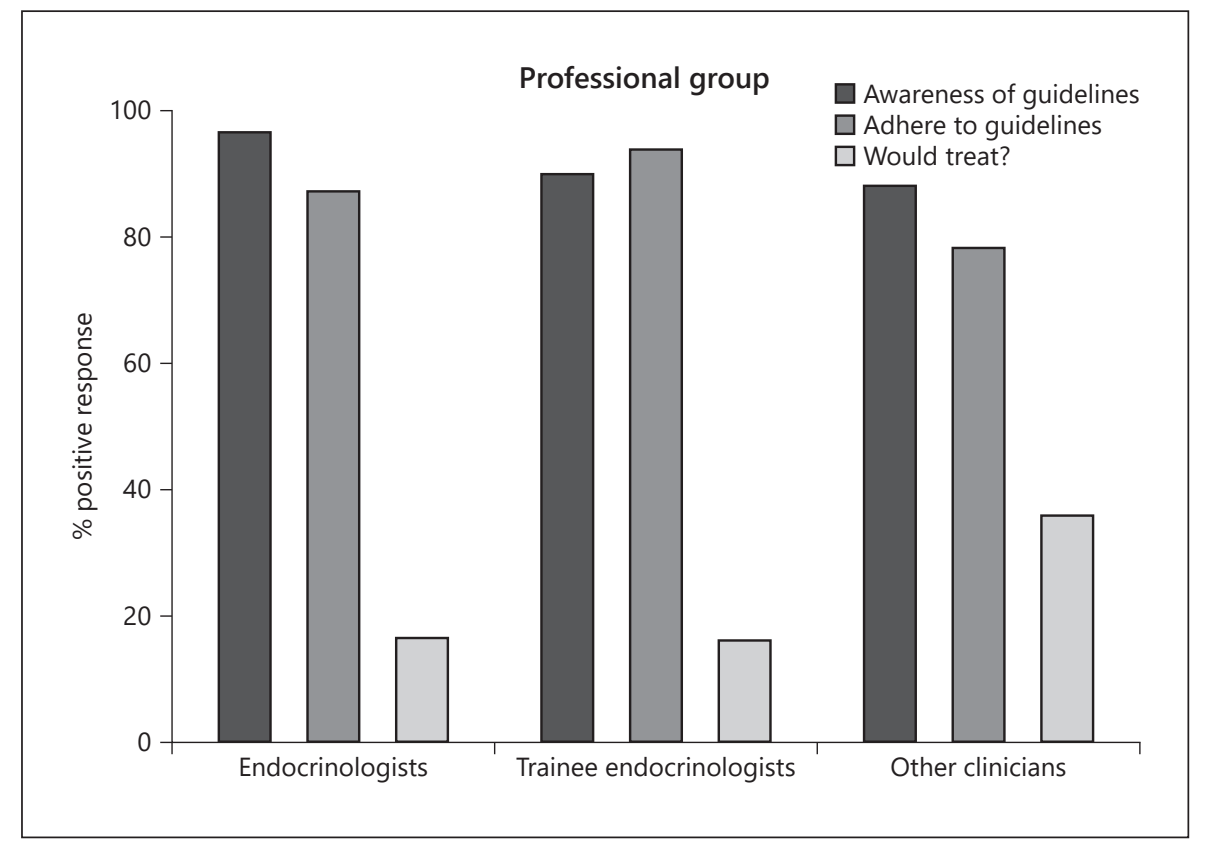

other regions. Eighty-four percent of the respondents were endocrinologists including trainees; the remaining respondents were other specialists (such as ear, nose, and throat or general medical physicians) or did not disclose their area of specialism or practice. Slightly more than half of the respondents $(50.8 \%)$ had extensive experience with more than 20 years of practice since qualifying. Some respondents provided answers for only parts of the survey and hence the denominator differs for each of the results described below.

\section{Treatment Decision of Older Person with Subclinical} Hypothyroidism

After excluding those who were "unsure," 462 respondents provided a response to this question. The majority (366, 79.2\%) stated that they would not treat an 80-yearold gentleman with persistent mild SCH and tiredness with LT4; the remaining respondents (20.8\%) stated that they would treat. Non-specialist clinicians were more likely to treat than specialist endocrinologists (Fig. 1). In the multivariable binary logistic regression model $(n=$ 458 who provided complete responses to the included variables), non-specialists were more than 3 times as likely as endocrinologists to treat the older patient, with an odds ratio (95\% CI) of 3.26 (1.45-6.47). Furthermore, the country/region of practice was a significant predictor of treatment preferences, with clinicians in North America more likely to treat than their peers from other parts of the world (Fig. 2). North American clinicians including endocrinologists were more than twice as likely to treat an older person with SCH compared to other areas, with an odds ratio of 2.24 (1.25-3.98). The sex and age group of the responder was not associated with treatment choices. It is pertinent to note that the American Thyroid Association is the only society of those that participated in this survey that does not explicitly recommend against treatment of older people with SCH but does advocate screening for thyroid dysfunction (Table 2). Furthermore, there was a statistically significant negative correlation between decision to treat the older $\mathrm{SCH}$ person and adherence to guidelines ( $\mathrm{phi}$ coefficient $=-0.47, p<$ $0.001)$.

\section{Awareness of and Adherence to Guidelines Regarding Management of Older Subclinical Hypothyroid Patients}

Once responses from those who were "unsure" were excluded $(n=16)$, a total of 516 clinicians provided a response to this question. Of these, the vast majority ( $n=$ $491,93.9 \%$ ) stated that they were aware of the guidelines and the characteristics of those with complete data $(n=$ 473) are described in online supplementary Table 1. Endocrinologists including trainees were more likely to be aware of these guidelines (89\%) than non-endocrinologists (74.7\%; Fig. 1). In the multivariable binary logistic regression model ( $n=441$ with complete responses to the 
Fig. 2. Frequency of awareness of and adherence to clinical guidelines, and likelihood of treating an older person with subclinical hypothyroidism, by country/region. The denominators for each region were: Europe $=221$, North America $=132$, North Africa (including Egypt) $=28$, South Africa $=22$, Latin America $=40$, other regions $=30$.

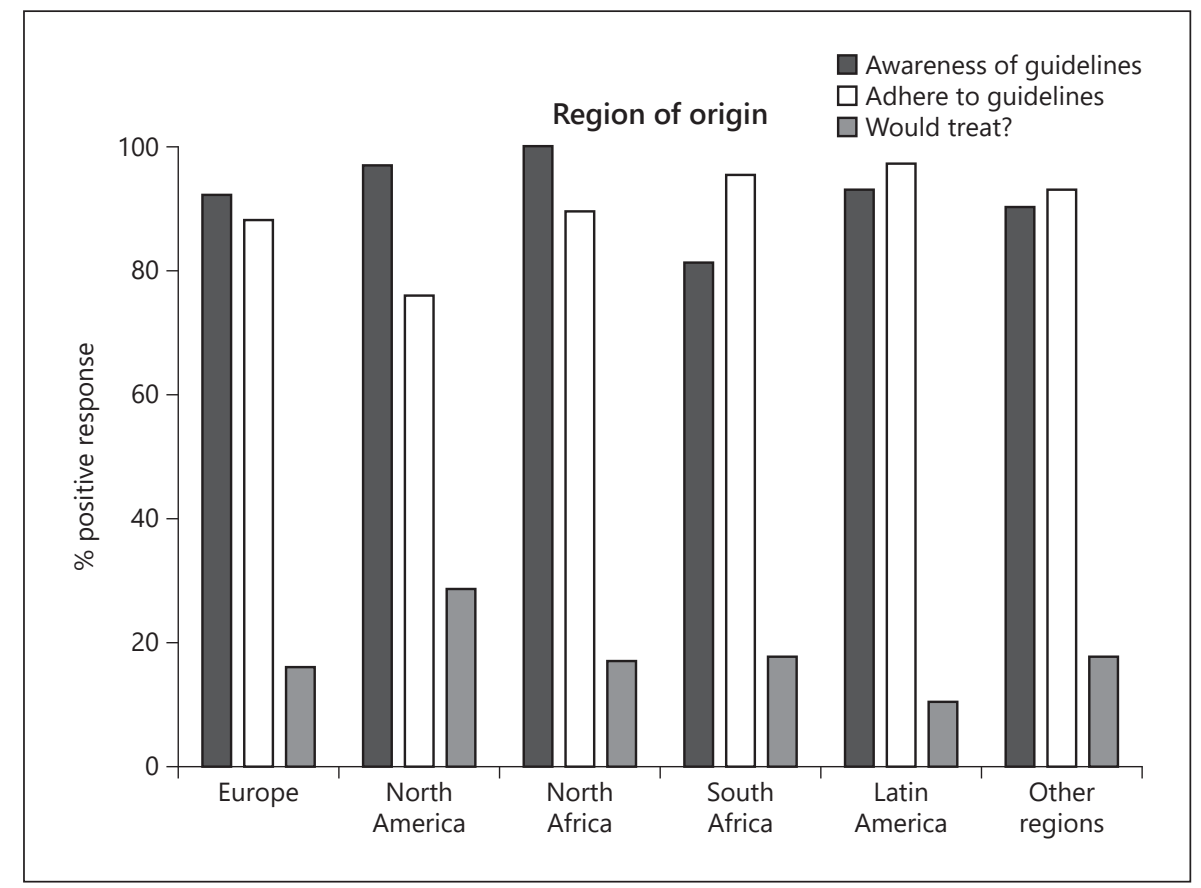

Table 2. Clinical guidelines pertaining to the management of subclinical hypothyroidism by various thyroid/endocrine societies and the percentage of their members that would treat an older person with subclinical hypothyroidism

\begin{tabular}{|c|c|c|c|}
\hline Society [ref.] & Recommendations & $\begin{array}{l}\text { Percentage who } \\
\text { would treat }\end{array}$ & $\begin{array}{l}\text { Recommendations on screening for } \\
\mathrm{SCH} \text { in the general population }\end{array}$ \\
\hline European Thyroid Association [17] & $\begin{array}{l}\text { In }>70 \text {-year-old people: } \\
\text { TSH }<10 \mathrm{mIU} / \mathrm{L} \text { : against treatment } \\
\mathrm{TSH} \geq 10 \mathrm{mIU} / \mathrm{L} \text { : consider treatment if clear symptoms } \\
\text { or at high vascular risk }\end{array}$ & 16.7 & No recommendations \\
\hline American Thyroid Association [20] & $\begin{array}{l}\text { No direct recommendation for or against treatment } \\
\text { based on age }\end{array}$ & 29.4 & $\begin{array}{l}\text { Specific groups for screening } \\
\text { including adults at age } 35 \text { years and } \\
\text { every } 5 \text { years thereafter }\end{array}$ \\
\hline Latin American Thyroid Society [18] & $\begin{array}{l}\text { If } \mathrm{TSH}<10 \mathrm{mIU} / \mathrm{L} \text { : } \\
\text { against routine treatment of elderly }(>65 \text { years }) \text { and } \\
\text { very elderly ( }>80 \text { years) }\end{array}$ & 10.9 & Not recommended \\
\hline $\begin{array}{l}\text { Society of Endocrinology, Metabolism } \\
\text { and Diabetes of South Africa [19] }\end{array}$ & $\begin{array}{l}\text { If } \mathrm{TSH}<10 \mathrm{mIU} / \mathrm{L} \text { : } \\
\text { consider a trial of therapy in specific groups aged } \\
<65 \text { years }\end{array}$ & 18.5 & Not recommended \\
\hline
\end{tabular}

included variables), endocrinologists including trainees were nearly 2 times more likely to be aware of the guidelines than other specialists, with an odds ratio $(95 \% \mathrm{CI})$ of 1.87 (1.45-2.33). The age group and gender of the respondent were not significantly associated with awareness of the guidelines. Awareness of guidelines was high (>90\%) in most parts of the world except amongst clini-

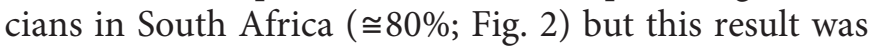

not statistically significant in the multivariable binary logistic regression analysis.

Overall, of the 491 respondents who were aware of the guidelines, $87.2 \%$ stated that they always adhere to the guidelines or follow them with certain exceptions when managing the older person with $\mathrm{SCH}$. However, there was variation within clinical roles and by regions. Only half of other specialists were likely to follow guidelines, 
Fig. 3. Perceived improvement in prescribing behaviour of LT4 in managing older persons with $\mathrm{SCH}$ as a result of clinical guidelines across various parts of the world. * Indicates 95\% CI; rest are 98.3\% CI. Main analysis was performed in all responders, whereas sensitivity analysis was performed after excluding those who were "unsure" or provided "other" responses.

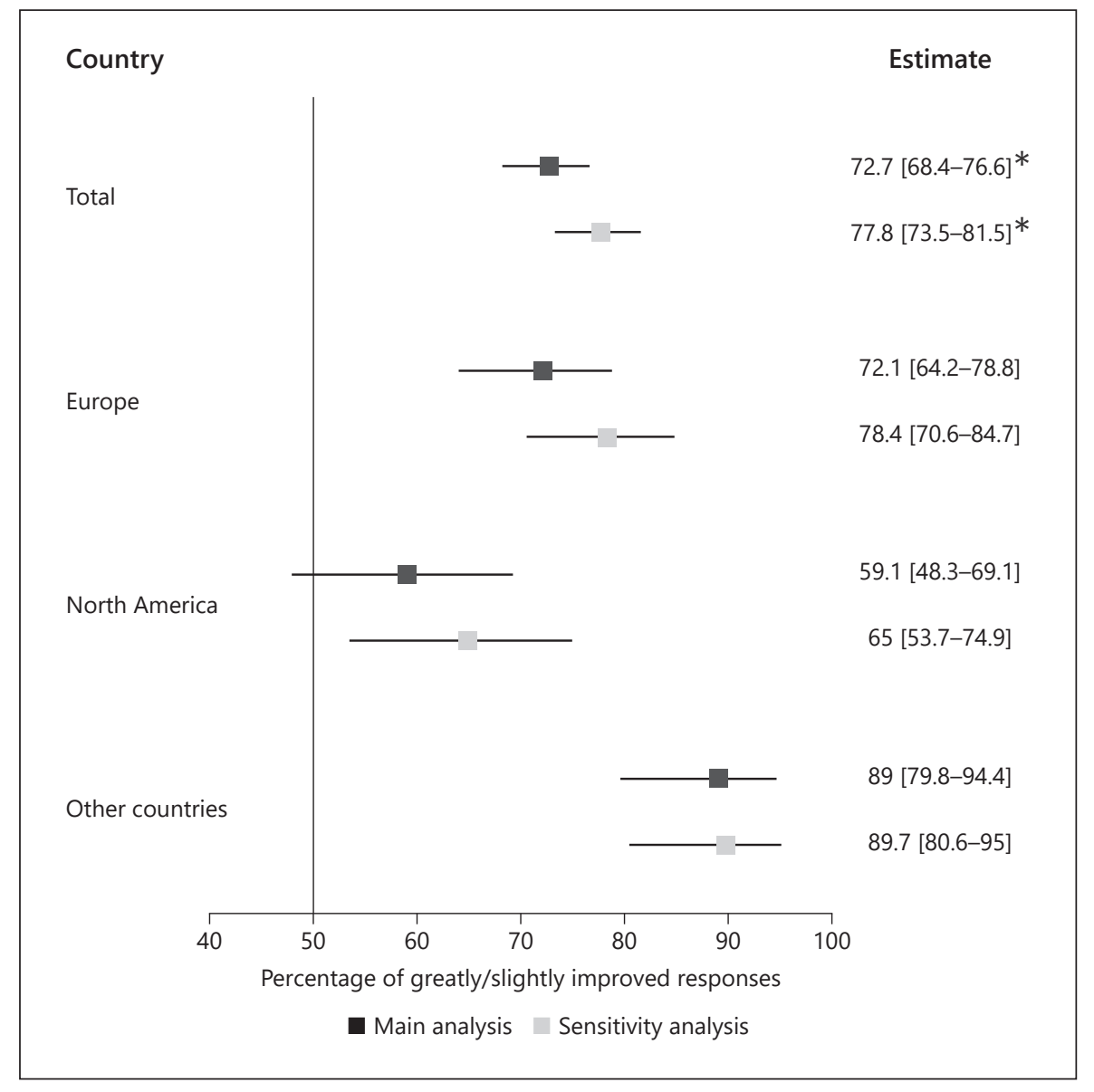

whereas $88 \%$ of endocrinologists stated that they always followed these guidelines or with certain exceptions (Fig. 1). Almost a quarter of clinicians (23.3\%) from North America stated that they sometimes or never follow these guidelines, whereas this frequency ranged between 2.3 and $11.2 \%$ for other regions of the world (Fig. 2).

\section{Excessive LT4 Prescribing and whether Guidelines Had Improved Prescribing}

Two thirds of respondents felt that there had been excessive prescribing of LT4 in the older SCH population prior to the guidelines being formulated (online suppl. Table 2). Furthermore, the majority of respondents felt that guidelines had improved LT4 prescribing (online suppl. Table 3).

\section{Is There Evidence for Change in Care across Several Parts of the World?}

To assess if participants felt there was an improvement in prescribing behaviour across parts of the world, we fo- cused our analyses on the participants who were aware of the guidelines. After excluding 19 participants with missing data, we analysed responses from 472 participants. If the guidelines had no effect on clinical practice, we would expect that, on average, opinions on the issue of the guidelines influencing prescribing behaviour in the management of an older person with SCH would be equally divided (i.e., 50-50 split between those who felt it improved their prescribing behaviour and those who did not feel it had a clear effect). Overall, across all countries/regions sampled, the evidence suggests that opinions are unlikely to be equally divided. Rather, participants were more likely to acknowledge that the guidelines had helped to improve their prescribing behaviour $(72.7 \%$, 95\% CI [68.4$76.6], p<0.001)$. Due to the small sample sizes of regions outside Europe and North America, we merged them into a single group "Other Countries" $(n=118)$. For the subgroup analysis, we report the $98.3 \% \mathrm{CI}$ instead to adjust for multiple comparisons using the Bonferroni correction. Within Europe, we found evidence that participants 
were more likely to report that the guidelines were helpful in improving prescribing behaviour $(72.1 \%, 98.3 \% \mathrm{CI}$ [64.2-78.8], $p<0.001)$. This was also the case for the "Other Countries" group (89\%, 98.3\% CI [79.8-94.4], $p<$ $0.001)$. However, we did not find evidence for the same pattern of results for North America (59.1\%, 98.3\% CI [48.3-69.1], $p=0.14$ ).

In the sensitivity analysis, after exclusion of "unsure" and "other" responses, results, overall, were consistent across all countries sampled, whereby participants were more likely to acknowledge that the guidelines had helped to improve their prescribing behaviour $(77.8 \%, 95 \%$ CI [73.5-81.5], $p<0.001)$. The results from the original analysis and sensitivity analysis provide robust evidence for a beneficial effect of the guidelines worldwide - with the exception of North America, whose results were dependent on how ambiguous responses were treated (Fig. 3).

\section{Discussion}

Most clinicians would not treat an older individual with mild SCH with LT4 therapy and are aware of the relevant guidelines pertaining to this topic. However, there is wide variation between various clinicians and regions of the world with regard to treatment practices and awareness of these guidelines. This international survey suggests that dissemination of these guidelines to other clinical groups other than endocrinologists is required.

The symptoms of hypothyroidism tend to be vague and non-specific. In the Colorado Thyroid Disease Prevalence Study, 4 or more symptoms of hypothyroidism were present in approximately $25 \%$ of those with overt hypothyroidism, $20 \%$ of those with $\mathrm{SCH}$, and in $17 \%$ of euthyroid patients [21]. Therefore, one of the challenges faced by clinicians is to accurately diagnose and manage the underlying cause of such common symptoms. Thyroid function tests are one of the most frequently requested biochemical tests [22]. It is thus not surprising that some clinicians may have a low threshold to treat marginally raised serum TSH levels to assess if "normalising" TSH may improve the patient's symptoms.

The management of SCH continues to be the subject of debate in both younger and older patients [23, 24]. Whilst the lack of evidence of benefit of treatment is inconclusive in younger patients, the data to support observational management is more convincing in older individuals [25]. The mechanism involved in the rise in serum TSH in older individuals is unclear [26]. The rise in serum TSH with age, however, is not associated with adverse outcomes [25]. Furthermore, randomised controlled trials of LT4 in older individuals with mild SCH have not shown any benefit with regard to improving cognition, symptoms, or quality of life [27-30]. Observational data from general practice also suggests that treatment of $\mathrm{SCH}$ in older individuals is not associated with any cardiovascular benefit [31]. In addition, one in 10 older individuals treated with LT4 demonstrates biochemical evidence of over-treatment, which persists for at least 2 years in a substantial proportion [32].

Guidelines recommend that the age of the patient should be considered when treatment of $\mathrm{SCH}$ is being planned. The guidelines from the European Thyroid Association are probably the most prescriptive in this regard [17]. They suggest that individuals older than 70 years and whose serum TSH is $<10 \mathrm{mIU} / \mathrm{L}$ should not be treated with LT4 and should have their thyroid function monitored regularly. Clinical practice guidelines sponsored by the American Thyroid Association and the American Association of Clinical Endocrinologists are not as prescriptive but do state that "The normal TSH reference range changes with age. If an age-based upper limit of normal for a third generation TSH assay is not available in an iodine sufficient area, an upper limit of normal of 4.12 should be considered" [20]. Similarly, Latin American Thyroid Society recommendations are "against routine treatment for elderly ( $>65$ years) and very elderly ( $>80$ years) patients with SCH at TSH levels $<10 \mathrm{mIU} / \mathrm{L}$ [18]. The Society for Endocrinology, Metabolism and Diabetes of South Africa recommends that age of the patient, their thyroid peroxidase status, and specific criteria (symptoms, vascular risk, pregnancy status, etc.) should be considered particularly when contemplating treatment [19].

The results of this survey suggest that most clinicians in our sample are aware of the relevant guidelines that recommend against treatment in managing older people with $\mathrm{SCH}$. In addition, adherence to these guidelines is, in general, quite high and seems to have impacted on clinicians' clinical practice. Nonetheless, more work is required to increase the implementation of these guidelines in specific groups such as clinicians from North America. It is interesting that clinicians in North America have a higher propensity to prescribe LT4 in an older patient with $\mathrm{SCH}$ and the regional guidelines from that area are the least prescriptive. It would seem desirable for the thyroid professional societies to formulate joint guidelines for treatment considerations and promote internationally consistent practices. It should, however, be noted that other factors, such as the differences in health care and 
reimbursement schemes, may also influence prescribing decisions. The lack of high-quality randomised controlled trials in SCH until recently may also be a factor that influences a clinicians' decision to treat symptomatic patients. In addition, a relevant group of clinicians to survey would be a large representative sample of GPs as the majority of $\mathrm{SCH}$ is managed in the community. Furthermore, any revisions to existing guidelines or formulation of new recommendations should include members of GP professional bodies.

This survey has several strengths. It included several regions of the world and respondents included endocrinologists as well as other clinicians. Since the guidelines have been developed by scientific bodies between 2012 and 2015, the current survey has also provided clinicians with adequate time to be able to consider and to adopt them in clinical practice. This international survey has weaknesses too. A number of regions particularly in Asia, such as China, India, and Australia, were under-represented in this survey. It should be noted that relevant societies representing those regions were contacted but no response was received. In addition, the response rate was only $22 \%$. However, it is not unusual for web-based surveys to have such response rates [33]. Certain regions where English is not the native language had a much lower response rate (e.g., Latin American region). The majority of $\mathrm{SCH}$ is managed in the community and hence it would be desirable to survey GPs from the UK and other countries. In addition, surveys of clinicians' treatment decisions may be based on a number of other factors that are not provided in a short clinical vignette and thus their responses may vary in practice.

In conclusion, this international survey suggests that the majority of clinicians would not treat an older person with mild SCH and are aware of the guidelines to this effect. However, certain groups of clinicians such as nonendocrinologists and those from North America are more likely to treat an older person with SCH than their endocrinology counterparts from elsewhere. More research is required to understand the barriers to implementing these guidelines by these groups. Finally, steps need to be taken to ensure that these guidelines are disseminated more widely, particularly in the non-endocrine community.

\section{Acknowledgments}

We are very grateful to the following individuals (and their teams) for facilitating the circulation of the electronic questionnaire to members of their respective organisations: Prof. Leonidas

Duntas, Secretary of the European Thyroid Association; Prof. Jacqueline Jonklaas, Secretary and Chief Operating Officer of the American Thyroid Association; Dr. Gabriella Brenta, President of the Latin American Thyroid Society; Dr. Tamer Elsherbiny, Vice president of the Alexandria Thyroid Association; Dr. Stephen Kirk, Clinical Director at NHS Newcastle Gateshead Clinical Commissioning Group; and Dr. Ankia Koetzee, President of the Society for Endocrinology, Metabolism and Diabetes of South Africa.

\section{Statement of Ethics}

The study was approved by the Newcastle University Faculty of Medical Sciences Ethics Committee (1650/2018). Participation in the survey was voluntary and respondents identity was not known unless they voluntarily provided identifying information.

\section{Conflict of Interest Statement}

All authors have no conflicts of interest to declare.

\section{Funding Sources}

There was no specific funding for this project.

\section{Author Contributions}

S.R., B.A., and N.O'B. substantial contributions to the conception or design of the work. S.R., B.A., D.T., S.H., N.O'B., and S.H.P. acquisition, analysis, or interpretation of data for the work. S.R., B.A., D.T., S.H., N.O'B., and S.H.P. drafting the work or revising it critically for important intellectual content. S.R., B.A., D.T., S.H., N.O'B., and S.H.P. final approval of the version to be published. S.R., B.A., D.T., S.H., N.O'B., and S.H.P. agreement to be accountable for all aspects of the work in ensuring that questions related to the accuracy or integrity of any part of the work are appropriately investigated and resolved.

\section{References}

Eur Thyroid J 2021;10:330-338

DOI: $10.1159 / 000509228$
1 Evered DC, Ormston BJ, Smith PA, Hall R, Bird T. Grades of hypothyroidism. BMJ. 1973 Mar;1(5854):657-62.

2 Peeters RP. Subclinical Hypothyroidism. N Engl J Med. 2017 Jun;376(26):2556-65.

3 Surks MI, Hollowell JG. Age-specific distribution of serum thyrotropin and antithyroid antibodies in the US population: implications for the prevalence of subclinical hypothyroidism. J Clin Endocrinol Metab. 2007 Dec; 92(12):4575-82.

4 Bremner AP, Feddema P, Leedman PJ, Brown SJ, Beilby JP, Lim EM, et al. Age-related changes in thyroid function: a longitudinal study of a community-based cohort. J Clin Endocrinol Metab. 2012 May;97(5):1554-62. 
5 Waring AC, Arnold AM, Newman AB, Bùzková P, Hirsch C, Cappola AR. Longitudinal changes in thyroid function in the oldest old and survival: the cardiovascular health study all-stars study. J Clin Endocrinol Metab. 2012 Nov;97(11):3944-50.

6 Pearce SH, Razvi S, Yadegarfar ME, MartinRuiz C, Kingston A, Collerton J, et al. Serum thyroid function, mortality and disability in advanced old age: the Newcastle 85+ study. J Clin Endocrinol Metab. 2016 Nov;101(11): 4385-94.

7 Ceresini G, Ceda GP, Lauretani F, Maggio M, Usberti E, Marina M, et al. Thyroid status and 6-year mortality in elderly people living in a mildly iodine-deficient area: the aging in the Chianti Area Study. J Am Geriatr Soc. 2013 Jun;61(6):868-74.

8 Gussekloo J, van Exel E, de Craen AJ, Meinders AE, Frölich M, Westendorp RG. Thyroid status, disability and cognitive function, and survival in old age. JAMA. 2004 Dec; 292(21):2591-9.

9 Taylor PN, Iqbal A, Minassian C, Sayers A, Draman MS, Greenwood R, et al. Falling threshold for treatment of borderline elevated thyrotropin levels-balancing benefits and risks: evidence from a large community-based study. JAMA Intern Med. 2014 Jan;174(1): 32-9.

10 Rodriguez-Gutierrez R, Maraka S, Ospina NS, Montori VM, Brito JP. Levothyroxine overuse: time for an about face? Lancet Diabetes Endocrinol. 2017 Apr;5(4):246-8.

11 Mitchell AL, Hickey B, Hickey JL, Pearce SH. Trends in thyroid hormone prescribing and consumption in the UK. BMC Public Health. 2009 May;9(1):132.

12 Ingoe L, Phipps N, Armstrong G, Rajagopal A, Kamali F, Razvi S. Prevalence of treated hypothyroidism in the community: analysis from general practices in North-East England with implications for the United Kingdom. Clin Endocrinol (Oxf). 2017 Dec;87(6):8604.

13 Razvi S, Korevaar TI, Taylor P. Trends, determinants and associations of treated hypothyroidism in the United Kingdom, 2005-2014. Thyroid. 2019 Feb;29(2):174-82.

14 Turner MR, Camacho X, Fischer HD, Austin PC, Anderson GM, Rochon PA, et al. Levothyroxine dose and risk of fractures in older adults: nested case-control study. BMJ. 2011 Apr;342:d2238.
15 Flynn RW, Bonellie SR, Jung RT, MacDonald TM, Morris AD, Leese GP. Serum thyroidstimulating hormone concentration and morbidity from cardiovascular disease and fractures in patients on long-term thyroxine therapy. J Clin Endocrinol Metab. 2010 Jan; 95(1):186-93

16 Sawka AM, Cappola AR, Peeters RP, Kopp PA, Bianco AC, Jonklaas J. Patient context and thyrotropin levels are important when considering treatment of subclinical hypothyroidism. Thyroid. 2019 Oct;29(10):1359-63.

17 Pearce SH, Brabant G, Duntas LH, Monzani F, Peeters RP, Razvi S, et al. 2013 ETA guideline: management of subclinical hypothyroidism. Eur Thyroid J. 2013 Dec;2(4):215-28.

18 Brenta G, Vaisman M, Sgarbi JA, Bergoglio LM, Andrada NC, Bravo PP, et al.; Task Force on Hypothyroidism of the Latin American Thyroid Society (LATS). Clinical Practice Guidelines for the Management of Hypothyroidism. Arq Bras Endocrinol Metabol. 2013; 57:265-91.

19 Dave JA. KlisieWicz A, Bayat Z, Mohamed NA, Stevens Z, Mollentze WF, Kinvig T. SEMDSA/ACE-SA guideline for the management of hypothyroidism in adults. Journal of Endocrinology. Metab Diabetes South Africa. 2015;20:18-26.

20 Garber JR, Cobin RH, Gharib H, Hennessey JV, Klein I, Mechanick JI, et al.; American Association of Clinical Endocrinologists and American Thyroid Association Taskforce on Hypothyroidism in adults. Clinical Practice Guidelines for Hypothyroidism in Adults: Cosponsored by the American Association of Clinical Endocrinologists and the American Thyroid Association. Thyroid. 2012;22:120035.

21 Canaris GJ, Manowitz NR, Mayor G, Ridgway EC. The Colorado thyroid disease prevalence study. Arch Intern Med. 2000 Feb;160(4): 526-34.

22 Allahabadia A, Razvi S, Abraham P, Franklyn J. Diagnosis and treatment of primary hypothyroidism. BMJ. 2009 Mar;338:b725.

23 Bekkering GE, Agoritsas T, Lytvyn L, Heen AF, Feller M, Moutzouri E, et al. Thyroid hormones treatment for subclinical hypothyroidism: a clinical practice guideline. BMJ. 2019; 365:12006.
24 Rapid response to Thyroid hormones treatment for subclinical hypothyroidism: a clinical practice guideline. [Accessed 5th December 2019]. Available from: https://www.bmj. com/content/365/bmj.12006/rr-14.

25 Leng O, Razvi S. Hypothyroidism in the older population. Thyroid Res. 2019 Feb;12(1):2.

26 Jansen SW, Akintola AA, Roelfsema F, van der Spoel E, Cobbaert CM, Ballieux BE, et al. Human longevity is characterised by high thyroid stimulating hormone secretion without altered energy metabolism. Sci Rep. 2015 Jun;5(1):11525.

27 Parle J, Roberts L, Wilson S, Pattison H, Roalfe A, Haque MS, et al. A randomized controlled trial of the effect of thyroxine replacement on cognitive function in communityliving elderly subjects with subclinical hypothyroidism: the Birmingham Elderly Thyroid study. J Clin Endocrinol Metab. 2010 Aug;95(8):3623-32.

28 Stott DJ, Rodondi N, Kearney PM, Ford I, Westendorp RG, Mooijaart SP, et al.; TRUST Study Group. Thyroid hormone therapy for older adults with subclinical hypothyroidism. N Engl J Med. 2017 Jun;376(26):2534-44.

29 Feller M, Snel M, Moutzouri E, Bauer DC, de Montmollin M, Aujesky D, et al. Association of thyroid hormone therapy with quality of life and thyroid-related symptoms in patients with subclinical hypothyroidism: a systematic review and meta-analysis. JAMA. 2018 Oct; 320(13):1349-59.

30 Mooijaart SP, Du Puy RS, Stott DJ, Kearney PM, Rodondi N, Westendorp RG, et al. Association between levothyroxine treatment and thyroid-related symptoms among adults aged 80 years and older with subclinical hypothyroidism. JAMA. 2019 Oct;322(20):1-11.

31 Razvi S, Weaver JU, Butler TJ, Pearce SH. Levothyroxine treatment of subclinical hypothyroidism, fatal and nonfatal cardiovascular events, and mortality. Arch Intern Med. 2012 May;172(10):811-7.

32 Mammen JS, McGready J, Oxman R, Chia CW, Ladenson PW, Simonsick EM. Thyroid hormone therapy and risk of thyrotoxicosis in community-resident older adults: findings from the Baltimore longitudinal study of aging. Thyroid. 2015 Sep;25(9):979-86.

33 Burch HB, Burman KD, Cooper DS, Hennessey JV, Vietor NO. 2015 survey of clinical practice patterns in the management of thyroid nodules. J Clin Endocrinol Metab. 2016 Jul;101(7):2853-62. 